\title{
Feminine to smell but masculine to touch? Multisensory congruence and its effect on the aesthetic experience
}

\author{
Aradhna Krishna ${ }^{a, *}$, Ryan S. Elder ${ }^{b}$, Cindy Caldara ${ }^{c}$ \\ ${ }^{a}$ Dwight F. Benton of Marketing, University of Michigan, Ann Arbor, MI, USA \\ ${ }^{\mathrm{b}}$ University of Michigan, Ann Arbor, MI, USA \\ ${ }^{\mathrm{c}}$ University of Grenoble, Grenoble, France
}

Received 9 June 2010; revised 22 June 2010; accepted 29 June 2010

Available online 7 August 2010

\begin{abstract}
We draw upon literature examining cross-modal sensory interactions and congruence to explore the impact of smell on touch. In line with our predictions, two experiments show that smell can impact touch in meaningful ways. Specifically, we show that multisensory semantic congruence between smell and touch properties of a stimulus enhances haptic perception and product evaluation. We explore this relationship in the context of two properties of touch, namely texture and temperature, and demonstrate that both smell and touch can have semantic associations, which can affect haptic perception and product evaluation depending on whether they match or not. In study 1, we focus on the semantic association of smell and touch (texture) with gender and in study 2 with temperature. Our results extend prior work on smell and touch within consumer behavior, and further contribute to emerging literature on multisensory interactions.

Published by Elsevier Inc. on behalf of Society for Consumer Psychology.
\end{abstract}

Keywords: Sensory aesthetics; Sensory perception; Semantic congruence; Smell; Touch

Full appreciation of an aesthetic product experience comes from recognition of beauty or good taste within that experience. Initially this appreciation stems from the visual components, as we typically view a product before we interact with it. Appropriately, a large amount of research devoted to understanding the aesthetic experience has dealt with vision (e.g., Hagtvedt \& Patrick, 2008; Raghubir \& Greenleaf, 2006; Reimann, Zaichkowsky, Neuhaus, \& Weber, 2010, Yang, Zhang, \& Peracchio, 2010). However, the full form of appreciation of an experience's beauty or good taste comes from the combination of visual and other sensory inputs. Indeed, the Greek origin of aesthetics - aisthanomai - means to feel with the senses or to perceive, leading to a formation of a gestalt aesthetic experience incorporating sensory perception,

\footnotetext{
is Author names are in reverse alphabetic order and authors contributed equally to the research. This research was started during Cindy Caldara's 6month fellowship with Aradhna Krishna.

* Corresponding author. R6354 Ross School of Business, Ann Arbor, MI 48109, USA. Fax: +1 7349368715.

E-mail addresses: aradhna@umich.edu (A. Krishna), rselder@umich.edu (R.S. Elder), cindy.caldara@upmf-grenoble.fr (C. Caldara).
}

emotions, and judgments (Berlyne, 1974). Similarly, per Rozin and Hormes (2009), sensory pleasure is foundational to aesthetic pleasure with the primary distinction being that the latter requires cognitive elaboration of the former. For instance, fine foods produce an immediate neural representation in sensory regions of the brain producing pleasure from taste; however, the cognitive thoughts associated with the consumption experience ultimately lead to heightened aesthetic perception and pleasure. In this paper, we focus on sensory pleasure which results from the combined effects of sensory inputs.

Our research examines the sensory experience and aesthetic pleasure resulting from the presence of smell on haptic (touch) perceptions. The effect of the combination of smell and haptics on sensory experience has not received attention within the marketing literature despite the acknowledgement that both scent and touch in isolation greatly impact consumer behavior (e.g., Morrin \& Ratneshwar, 2003; Peck \& Wiggins, 2006). We propose that semantic associations of the scent and the haptic properties of the stimuli, as well as the congruence of these associations, will determine haptic perceptions of the product and overall efficacy of the product derived from these haptic 
perceptions. The two dimensions of touch that we consider are texture and temperature.

We present two studies to exhibit the effect of smell on haptic perceptions. In the first study, we explore the impact of smell on haptic perceptions of texture. We show that both smell and texture can be considered masculine or feminine and there is a match on this semantic dimension, the object "feels" better to touch. In the second study, we explore the effects of smell on product efficacy which is primarily based on perceived temperature of the product. We demonstrate that smell can be considered hot or cold and when this semantic association of smell matches the temperature of the product, perceived product efficacy is higher. As such, across both studies we receive support for the hypothesis that multisensory semantic congruence between the senses of smell and touch can affect haptic perception and product evaluations.

We begin by reviewing relevant literature on sensory perception and aesthetics, and then on research exploring touch, smell, and multisensory interactions within consumer behavior. We also discuss research on cue congruence and semantic associations, our posited moderators of the effect of smell on touch. Following this literature review which establishes the foundation for our hypotheses, we discuss our two studies. We end with conclusions and limitations of our research.

\section{Literature review and hypotheses}

\section{Sensory perception and aesthetics}

Rozin (1999) provides detail regarding the connection between sensory inputs and aesthetic experience. According to his framework, pleasure can be divided into three elements: sensory, aesthetic, and mastery. As stated earlier, sensory pleasure is a fundamental, automatic response to stimuli, foundational to the formation of aesthetic pleasure. Aesthetic pleasure results from an elaboration of the sensory experience. For instance, consumption of a fine wine may lead to stimulation of taste buds and olfactory receptors generating sensory pleasure; however, the full aesthetic pleasure of the wine is derived from deliberation and elaboration of these sensory inputs - an activity that has necessitated its own vernacular. Mastery is the third element of pleasure, and is derived from accomplishment or expertise within a domain. We limit our focus to the former two elements of pleasure, namely aesthetic and sensory.

We posit that the degree of aesthetic pleasure derived from the sensory experience can ultimately be impacted by the level of semantic congruence between sensory inputs. We are specifically interested in the impact of smell on touch perceptions. As such, we next review relevant literature on both touch and smell, as well as recent literature exploring the effects of multisensory interactions on consumer behavior. Finally, we derive our hypotheses from literature on the consequences of sensory congruence.

\section{Touch}

The perception of haptics (i.e., touch with the hands) has received sparse attention both within the psychology and consumer behavior literatures, although this attention is increasing (Peck \& Childers, 2008). Within the consumer behavior literature, touch has been shown to enhance positive feelings in the context of interpersonal touch (Hornik, 1992), to improve confidence in product judgment when the environment allows physical inspection (McCabe \& Nowlis, 2003), as well as to enhance product evaluation when softness and texture vary, especially for high quality products (Grohmann Grohmann, Spangenberg, \& Sprott, 2007). Even when the haptic input is non-diagnostic for product judgment, it has been shown to impact taste evaluations (Krishna \& Morrin, 2008). Similarly, for some individuals merely touching a positively valenced item related to a message can impact the persuasiveness of the message (Peck \& Wiggins, 2006).

For many products, haptic perceptions are the dominant input to determining product quality. Indeed, touching products can lead to increased confidence in purchasing behavior, as well as heightened product quality beliefs (Peck \& Childers, 2003). In addition, recent research shows that merely imagining the touch experience can increase perceptions of ownership of the item (Peck \& Shu, 2009). This latter finding is particularly important given the increase of online shopping and virtual product interaction.

Touch plays an integral role within consumer behavior and sensory engagement. The bulk of the prior literature has focused on the touch property of texture, even though haptic characteristics of products vary along four dimensions: texture, hardness, temperature, and weight (Klatzky, Lederman, \& Matula, 1987). Our initial focus within the present research is on texture as well. However, we additionally explore the dimension of temperature. Experimentally, we choose products where either the texture or the temperature is a key product characteristic, and consequently will play a vital role in determining overall product quality.

Our aim is to contribute to the literature on touch within consumer behavior by showing how additional sensory inputs can influence haptic perceptions. Our specific focus in this regard is on the sense of smell, another emerging area of research within consumer behavior.

\section{Smell}

While a great deal of research on smell has focused on 2010 (e.g., Herz, 2004; Krishna, Lwin Morrin, \& Morrin, forthcoming; Lwin, Maureen, \& Krishna, forthcoming; Morrin, Lwin, \& Krishna, 2010; Morrin \& Ratneshwar, 2003), we focus specifically on the impact of smell on product evaluations. The exploration of smell and product evaluations has a storied past, dating back to the early 1930s. In a study exploring the effect of smell on products, Laird (1932) infused women's silk stockings with various smells and then took the stockings door to door to determine preferences for the items among housewives. Interestingly, the stockings infused with a floral smell were preferred over six times more than the unscented stockings, despite few mentions of the smell in respondent's decision making process. Subsequent research on the impact of smell on product evaluations has largely focused on ambient scent rather than product scent, and the results have been mixed 
(see Bone \& Ellen, 1999). Despite several papers exhibiting no effects of ambient scent on product evaluations (e.g., Morrin \& Ratneshwar, 2003), other research has shown improved product evaluations in the presence of scent (e.g., Bosmans, 2006; Mitchell, Kahn, \& Knasko, 1995). These studies exhibit the positive impact of an ambient scent in the retail environment and identify the variables moderating this impact, such as congruence of the scent with the product category, salience of the scent, and also motivation to correct the influence of extraneous cues. We aim to build on these studies, exhibiting effects of smell on the touch properties of products.

The somewhat tenuous findings of smell on product evaluations exhibit the need for future research exploring how and why smell affects consumer perceptions and evaluations. We propose that one key construct that has been neglected is the semantic nature of the smells. While a great deal of the prior literature has focused on the impact of smell valence on evaluations, we propose that smell can impact perceptions in a much more sophisticated manner through the transfer of semantic associations. These semantic associations are most commonly learned through repeated exposure to different smells in different contexts (e.g., lemon and cleaning products). We will elaborate more fully on the importance of these semantic associations when discussing sensory congruence.

\section{Multisensory interactions and consumer behavior}

The marketing literature has received a marked increase in scholarly attention devoted to the impact of sensory perception on consumer behavior (for a review see Peck \& Childers, 2008). Much of this exploration has focused on the effects of single senses on consumer behavior, that is, in isolation from the other senses. Research on the impact of smell on memory (Morrin \& Ratneshwar, 2003), music on shopping behavior (Yalch \& Spangenberg, 2000), and touch on feelings of ownership (Peck \& Shu, 2009) highlights some of the fascinating results from this primary focus.

Some recent studies within consumer behavior have also explored cross-modal interactions across various sensory perceptions. These studies include the effects of smell and sound (Mattila \& Wirtz, 2001), sound and vision (Russell, 2002), sound and smell (Spangenberg, Grohmann, \& Sprott, 2005), sound and perceived taste (Yorkston \& Menon, 2004), touch and taste (Krishna \& Morrin, 2008), vision and taste (Hoegg \& Alba, 2007), as well as multisensory cognitions and taste (Elder \& Krishna, 2010).

To elaborate on a few of these findings, Krishna and Morrin (2008) find that the haptic quality of the cup that water is consumed from alters the taste perceptions of the water. Specifically, the authors show that for individuals with little touch expertise, the non-diagnostic haptic cues conveyed through the cup affect overall taste evaluations, with the taste of the water being perceived as higher quality when in a firm versus flimsy cup. The inferred haptic meaning of the cups was transferred across sensory modalities to affect consequent taste perceptions.
In the area of sensory dominance, Hoegg and Alba (2007) show that the visual cues for orange juice can be more instrumental in driving perceptions than actual taste. Participants rated the perceived differences of three pairs of orange juice, with one of the pairs consisting of identical samples. The color of the orange juice was manipulated such that two of the four samples were natural orange juice color, whereas the others were darker in color. This color difference led participants to perceive two dissimilar tasting samples as more similar than two identical samples. That is, participants erroneously perceived the match in color to signify a match in taste. These results highlight the ambiguity of sensory experience and the reliance on multiple cues (including other sensory cues) to formulate perceptions.

\section{Sensory congruence}

We anticipate the impact of smell on haptic perceptions to be additionally driven by the semantic congruence across the sensory inputs. As in the prior literature, we define cue congruence to be the degree of fit among characteristics of a stimulus (Bone \& Ellen, 1999; Peracchio \& Tybout, 1996). Cue congruence is a highly relevant construct when studying the cross-modal interactions among senses. Specifically, it has been shown that the congruence of two stimuli result in faster reactions times of recognition (Laurienti et al., 2002), as well as improved information processing (Mandler, 1982). Neurophysiological research has additionally shown that congruence (vs. incongruence) of sensory inputs leads to faster integration of the sensory inputs and more accuracy on behavioral measures (Gottfried \& Dolan, 2003). We propose that congruence will lead to more positive haptic perception and more positive product evaluations.

In marketing, as mentioned earlier, Mattila and Wirtz (2001) showed that when coupled in a retail store environment, the use of scent and music improved approach behaviors when the arousing qualities of the two sensory dimensions were congruent. More recently, Spangenberg et al. (2005), studied the interactive effect of ambient scent and music in retail settings in the context of Christmas, showing that congruence between the two modalities improved store evaluations.

It is also fairly well established that congruity with expectation leads to moderately positive evaluations of products, because individuals enjoy products that conform to their expectations and that are predicable (Meyers-Levy \& Tybout, 1989). When the considered cue is congruent with expectations, then its attached positive affect is transferred to the overall evaluation (Fiske, 1982).

An interesting component of congruence is that it is determined by the appropriateness or fit of the semantic associations among the characteristics. Sensory inputs, due to their common associations with experiences, obtain semantic meaning. These semantic associations are shown across sensory modalities, including smell (Stevenson \& Boakes, 2003), and music (Meyers-Levy \& Zhu, 2010), and can affect perceptions and also actual behavior. Holland, Hendriks, \& Aarts (2005) show that the presence of a citrus scent, having semantic 
associations with cleaning, led participants to be more likely to clean their cubicles after eating cookies than a no scent condition. The authors claim that the presence of scents activates semantic associations, which subsequently impact behavior. While Holland et al. (2005) explicitly mention semantic associations of scent, some other research implicitly looks at the effect of semantic sense associations on product evaluation. For example, Spangenberg, Sprott, Grohmann, \& Tracey (2006) show that when gender of a retailer's ambient smell is congruent with the product being sold, then the perception of the product and store is much higher; Mitchell et al. (1995) show that cognitive elaboration is higher when the ambient smell is congruent with the product. Peck and Wiggins (2006) demonstrate that when congruent materials (bark of a tree, feather) are attached to the donation appeal brochure for an arboretum, donations increase versus when incongruent materials (steel wool, color swatch) are attached-this occurs for people who are motivated to touch.

While Holland et al. (2005), Spangenberg et al. (2006), Mitchell et al. (1995) and Peck and Wiggins (2006) focus on congruence between the semantic meaning of a scent and a product or behavior, we focus on congruence between semantic associations between two senses. Some prior research has effectively studied the congruence of semantic associations of two senses (e.g., Christmas music and Christmas scent; Spangenberg et al., 2005), but the fact that these associations were semantic in nature was not an integral part of their theory development. We maintain that, similar to scent, tactile properties will lead to semantic associations, such as firm haptics implying strong and soft haptics implying weak, or rough haptics suggesting masculine and smooth haptics suggesting feminine. We aim to show that as both smells and haptic perceptions can have semantic associations, the matching of these associations can impact haptic perception and product evaluation.

We propose that the meanings of scents and haptic properties, when matched, will lead to semantic congruence between smell and touch. We propose that this congruence will lead to more positive haptic perceptions. More specifically, we propose that, "multisensory semantic congruence will moderate the impact of smell on haptic perceptions, with congruence leading to more positive evaluations than incongruence."

We aim to test this hypothesis across two separate studies. In study 1, we explore the interaction of smell and touch within the domain of texture. Specifically, we show that evaluations of the haptic perception of paper are contingent upon the degree of semantic congruence between the smell and haptic inputs - the semantic aspect we focus on is femininity-masculinity. In study 2 , the semantic aspect of smell-touch that we consider is temperature (hot-cold) and we explore its effect on perceived effectiveness of gel-packs. Across both studies we show that multisensory semantic congruence between the smell and touch components of a product can lead to important consequences for product evaluation. While study 1 focuses very directly on the hedonic or aesthetic aspect of product evaluation (how the paper "feels"), study 2 focuses on perceived effectiveness of the product (how effective a gel-pack is in making the body/warm or cold, relieving pain, etc.) which in turn is related to how the gel-pack makes the individual "feel," i.e., the hedonic experience.

\section{Study 1-texture and smell: Paper study}

In study 1 we seek to explore the way congruence between semantic associations from smell and touch can impact haptic perceptions, specifically texture. As we are interested in drawing semantic associations from the smell to the haptic experience, we needed to find a way to match the stimuli. Congruence between smell and texture can exist on many dimensions. For the purpose of our research, we chose to operationalize congruence on the dimension of femininitymasculinity. The specific question to be addressed is whether a smell perceived as being more masculine or feminine can impact haptic quality perceptions of paper matched for congruity (i.e., paper perceived as being more masculine or feminine). As hypothesized, we anticipate congruence between smell and touch to lead to more positive haptic perceptions than incongruence. In order to ensure proper operationalization of such congruence we carefully pretested both the scents as well as the paper on several key dimensions.

\section{Method}

\section{Pretests}

We conducted a series of pretests to 1) determine choice of the scents, 2) determine choice of paper, and 3) ensure the congruence between the paper and scents.

\section{Pretest 1: Choice of feminine and masculine scent}

We initially selected 14 colognes and perfumes that were available on the market, but not widely recognized. We had 12 participants rate each smell on pleasantness, likeability, familiarity, as well as the perceived gender of the scent ( $1=$ very feminine, $9=$ very masculine $)$. We counterbalanced the order of presentation of the smells, and no order effects were present. Our objective was to obtain two smells that differed significantly on the gender dimension, but were equal on each of the other dimensions. Of the smells, two completely satisfied our criteria. Interestingly, the two smells were from the same manufacturer. Specifically, we chose Hanae Mori Black as our masculine smell and Hanae Mori White as our feminine smell. Each was equated on the dimensions of pleasantness $\left(M_{\mathrm{black}}=\right.$ $\left.5.25, M_{\text {white }}=5.67\right)$, likeability $\left(M_{\text {black }}=5.00, M_{\text {white }}=5.42\right)$, and familiarity $\left(M_{\text {black }}=5.67, M_{\text {white }}=5.50\right.$; all $\left.p \mathrm{~s}>.5\right)$, but differed significantly on perceived gender $\left(M_{\mathrm{black}}=6.33, M_{\text {white }}=3.67\right.$, $t(11)=2.64, p<.05)$. Both smells were also equidistant from the midpoint (5) on perceived gender, giving us confidence that the masculine smell is perceived as masculine as the feminine smell is perceived as feminine.

\section{Pretest 2: Choice of paper}

In order to choose papers that carried a gender semantic association, we selected texture as the key dimension. Our hypothesis is that smooth paper will be perceived as more 
feminine and rough paper will be perceived as more masculine. We were careful to not confound texture with paper thickness; thus, we selected several papers from a local art store that had equal weight. For the rough paper, we selected artists' watercolor paper. For the smooth paper we selected a smooth posterboard. The two papers were the same thickness (as measured by paper weight) and color (white), but varied dramatically on texture.

We pretested our paper on 21 participants for gender perceptions $(1=$ very feminine, $9=$ very masculine $)$. As expected, the rough paper was perceived as being masculine, and the smooth paper was perceived as being feminine $\left(M_{\text {rough }}=6.62, M_{\text {smooth }}=2.86, t(20)=-10.32 ; p<.001\right)$. We are therefore confident that our paper selection is capturing our intended dimensions of gender. In order to determine if a masculine or feminine smell was congruent with rough and smooth paper, respectively, we conducted a final pretest.

\section{Pretest 3: Pretest on paper-scent congruence}

Our hypothesis is that the perceived fit or congruence between the paper and the smell, based on the semantic associations established in the prior pretests, will have an impact on haptic perceptions. Consequently, we conducted a third pretest to determine this congruity. We prepared the four stimuli options to be used in study 1 (smooth-feminine, smoothmasculine, rough-feminine, rough-masculine) and had 20 participants evaluate the congruence of the smell-touch pair. This was captured by two nine-point scales $(1=$ very inappropriate, $9=$ very appropriate; $1=$ very poor fit, $9=$ very good fit; $r=.83)$. For the smooth paper, the feminine smell $(M=6.64)$ was perceived as more congruent than the masculine smell $(M=3.79, p<.001)$. Similarly, for the rough paper the masculine smell $(M=6.29)$ was perceived as more congruent than the feminine smell $(M=4.00, p<.001)$.

\section{Design}

We employed a 2 (paper: rough vs. smooth) $\times 2$ (smell: feminine vs. masculine) between subjects factorial design. Preparation of the stimuli involved cutting two inch squares of paper, and then applying one spray of the smell to each swatch of paper. The paper swatches were then transferred to a resealable plastic bag and left for approximately $24 \mathrm{~h}$ prior to the study.

\section{Procedure}

Seventy-three marketing undergraduate students at a large Midwestern university participated in study 1 in groups ranging from 5 to 10 in exchange for course credit. To ensure that the smells did not compete with one another, sessions were run by smell condition. Upon entering the lab, participants were given a folder containing the instructions, the questionnaire, as well as the re-sealable bag with the smell sample. In addition, in front of each participant was a small white cup half-full of coffee beans.

The instructions informed participants that they would be evaluating a new smell that is currently on the market. They were told to smell the cup of coffee beans with three deep breaths prior to smelling the smell. This was done in order to refresh their scent palette (Secundo \& Sobel, 2006). Participants next opened the re-sealable bag and were instructed to pick up the paper with their right hand and hold it under their nose to smell it three times. Following this, participants placed the paper back in the bag and proceeded to their questionnaire. Importantly, no mention was made during the procedure to the paper.

\section{Dependent measures}

As we had disguised the study as an evaluation of smells, we began the questionnaire by asking participants to rate their opinion of the scent on pleasantness and likeability. We also included the gender of the smell as a manipulation check on the smell used ( $1=$ very feminine smell, $9=$ very masculine smell). After answering questions regarding the smell, participants next evaluated the texture of the paper on two dimensions: how the paper felt in their hands $(1=$ not at all a good feel, $9=$ very good feel), and the texture of the paper $(1=$ very poor texture, $9=$ very good texture) - the haptic perception scale. We also asked for the participants' gender to ensure that neither the smell nor the haptic perceptions of the paper were affected by fit with gender. We included gender as a covariate in subsequent analyses; however, in none of the cases did gender have a significant impact on our results, hence we will not discuss it further.

\section{Results and discussion}

We began our analysis by examining the manipulation checks for smell. An ANOVA run on the perceived gender of the smells reveals only a significant main effect of smell, wherein the masculine smell is perceived as more masculine than the feminine smell $\left(M_{\text {masculine }}=6.63, M_{\text {feminine }}=2.26, F(1,69)=108.99\right.$, $p<.01)$.

We have hypothesized that the congruence of the smell and texture of the paper will lead to enhanced haptic perceptions of the paper. Indeed, this is what we find. An ANOVA run on the haptic perception scale revealed a significant main effect of paper, with the smooth paper being rated with more positive haptic perceptions than the rough paper $\left(M_{\text {smooth }}=5.77\right.$, $\left.M_{\text {rough }}=4.86, F(1,69)=8.11, p<.01\right)$. More importantly, and as hypothesized, the interaction of smell and paper was also significant $(F(1,69)=9.89, p<.01)$. Planned follow-up contrasts on the interaction reveal that within the smooth paper condition, the feminine smell led to significantly more positive haptic perceptions than the masculine smell $\left(M_{\text {feminine }}=6.25\right.$, $\left.M_{\text {masculine }}=5.32, t(69)=2.19, p<.05\right)$. Similarly, within the rough paper condition, the masculine smell led to significantly more positive haptic perceptions than the feminine smell $\left(M_{\text {feminine }}=4.43, M_{\text {masculine }}=5.41, t(69)=2.26, p<.05\right)$. These results provide support for the hedonic consequences of smelltouch congruence, as well as the semantic associations that smells and haptic experiences can hold.

The results from study 1 show that multisensory semantic congruence can lead to enhanced haptic perceptions. 
Specifically, we explored the impact of smell on touch and show that when the smell was congruent with the haptic properties of the stimulus (paper), participants rated the haptic perceptions more positively than when the smell was not congruent with the haptic properties. Of theoretical importance, our results show that both smells and haptic qualities can have specific meanings-both smell and texture were considered masculine or feminine. In turn, when smell and touch are congruent in these meanings, we obtain the effects that the congruence of these two sensory modalities leads to more positive evaluations of haptic perceptions than when they are incongruent.

The results from study 1 are supportive of our hypothesis that both smells and haptic experiences can have semantic associations. Furthermore, we exhibit that the congruence of these semantic associations leads to more positive perceptions. To test the robustness of the sensory semantic congruence effect, in the next study, we make two changes. We manipulate semantic congruence between smell and touch along the aspect of temperature (and not gender as we did in study 1). Second, study 1 explores the impact of smell on the texture property of touch, whereas study 2 focuses on the temperature property of touch.

\section{Study 2-temperature and smell: Gel-pack study}

In order to experimentally test our hypothesis, we selected smells that varied along the temperature dimension. Additionally, we selected a product (therapeutic gel-pack) that could be used both hot and cold and is evaluated for efficacy based off of haptic perceptions. We next describe our pretesting of smells prior to elaborating on study 2 .

\section{Method}

\section{Pretest}

The pretest was conducted in order to select two smells differing only on the temperature dimension. We selected 6 different essential oils, three of which we anticipated to rate as warm smells, and three we anticipated to rate as cold smells. The specific smells chosen were warm vanilla sugar, pumpkin cinnamon, and Mexican hot chocolate for warm, and eucalyptus- spearmint, sea-island cotton, and tranquil mint for cold. We put one drop of each smell onto a piece of blotting paper and had 19 participants rate the smells on the dimensions of pleasantness, likeability, familiarity, medicinal qualities, as well as temperature $(1=$ very cold smell, $9=$ very warm smell). Our objective was to obtain two smells that differed only on perceived temperature. Of the smells, pumpkin cinnamon was rated as the warmest and eucalyptus-spearmint was rated as the coldest. However, although the two smells matched on most dimensions, eucalyptus-spearmint was rated as significantly more medicinal than pumpkin cinnamon. As participants are to evaluate the efficacy of therapeutic gel-packs, we eliminated this potential confound by selecting the second coldest smell, sea-island cotton. Thus, we conservatively test our hypothesis by selecting a smell closer to the midpoint on temperature. The two selected smells were equal on four of the five dimensions (all $p>.6$ ), and differed significantly only on the temperature dimension $\left(M_{\text {cinnamon }}=6.21, M_{\text {sea island cotton }}=4.23, t(18)=2.33\right.$, $p<.05)$. We therefore used pumpkin cinnamon as our warm smell and sea-island cotton as our cold smell.

\section{Design}

We employed a 2 (gel-pack temperature: warm vs. cold) $\times 2$ (smell temperature: warm vs. cold) between subjects factorial design. In order to infuse the gel-packs with smell and to remove any identifying information, we had a professional seamstress sew custom pouches made out of black fabric to cover each gel-pack. Prior to the experimental sessions the pouches were infused with the appropriate smell with one spray per pouch. The gel-packs were also prepared according to session, with those in the cold conditions kept in the freezer for $24 \mathrm{~h}$ until $5 \mathrm{~min}$ before each session, and those in the warm conditions heated up in a microwave for $60 \mathrm{~s}$ at full power also 5 min before each session. Gel-packs have also been used before in prior temperature studies. Williams and Bargh (2008) used cold and hot gel-packs to show that people who felt temperature warmth (held warm gel-packs) acted more generously than those who did not (held cold gel-packs).

\section{Procedure}

One-hundred and sixteen marketing undergraduate students participated in study 2 in exchange for course credit. Each session was run with only one smell and one temperature to reduce possible effects of ambient smell as well as to ensure that participants did not inadvertently affect results by mentioning the temperature of the gel-packs. Session size ranged from 4 to 10.

Upon entering the lab, participants were greeted by the experimenter and seated in front of a laptop computer. All participants in a session began at the same time, with the instructions that they would be evaluating an aromatherapy gelpack. The experimenter then passed out the gel-packs and instructed participants to smell the gel-pack once and then place it on the back of their left hand for $15 \mathrm{~s}$. Following the $15 \mathrm{~s}$, the experimenter removed the gel-packs from the room and participants proceeded to answer a questionnaire evaluating the gel-packs.

\section{Dependent measures}

Participants first listed any thoughts or feelings they had while evaluating the gel-packs. Following this thought listing, participants rated the gel-pack on several key dimensions. Specifically, participants rated how quickly the gel-pack would work in treating pain, how effective the gel-pack would be in treating pain, as well as how well the gel-pack warmed or cooled their hand $(\alpha=.86)$ - the haptic perception scale. This last question regarding how well the gel-pack warmed or cooled their hand was altered by condition, such that those in the warm gel-pack conditions rated how quickly the gel-pack warmed 
their hands, while those in the cold gel-pack conditions rated how quickly the gel-pack cooled their hands. Following this evaluation of the gel-pack effectiveness, participants evaluated the smell on its pleasantness, likeability, and temperature.

\section{Results and discussion}

An ANOVA run on the perceived temperature of the smells reveals a significant main effect of smell, wherein the warm smell is perceived as being warmer than the cold smell $\left(M_{\text {cold }}=5.27, M_{\text {warm }}=6.40, F(1,112)=13.53, p<.01\right)$, and also a main effect of gel-pack temperature $\left(M_{\text {cold }}=5.01\right.$, $\left.M_{\text {warm }}=7.07, F(1,112)=43.17, p<.01\right)$. The first main effect (smell) serves as a manipulation check. The second effect (gelpack temperature) is not entirely surprising, as the stimulus itself was either warm or cold and that may have influenced smell perceptions.

Our primary focus for study 2 , however, is on the effects of congruence between smell and touch on gel-pack evaluations. We conducted a $2 \times 2$ ANOVA on our scale of gel-pack evaluations with gel-pack temperature and smell temperature as the independent variables. We get a significant main effect of gel-pack temperature, with the cold gel-pack rated as more effective than the warm gel-pack $\left(M_{\text {cold }}=6.05, M_{\text {warm }}=5.46\right.$, $F(1,112)=4.53, p<.05)$. More importantly, and as hypothesized, we also get a significant interaction between the two factors $(F(1,112)=9.94, p<.01)$. Planned follow-up contrasts on the means reveal the hypothesized pattern. Specifically, we see that for the warm gel-pack, the warm smell leads to significantly more positive evaluations than the cold smell $\left(M_{\text {warm }}=5.97, M_{\text {cold }}=4.99, t(112)=2.36, p<.05\right)$. Similarly, for the cold gel-pack, the cold smell leads to significantly more positive evaluations than the warm smell $\left(M_{\text {cold }}=6.40\right.$, $\left.M_{\text {warm }}=5.70, t(112)=2.09, p<.05\right)$.

The results of study 2 add further support to our hypothesized effects of multisensory semantic congruence between smell and touch. We replicated the results from study 1 with a new property of touch, namely, temperature. We show that smells can have a semantic meaning of warm and cold. Whether or not this semantic meaning of temperature for smell matches the haptic temperature of an object can impact the perceived haptic feeling of the product. When the smell of the gel-pack was infused with sea-island cotton (pumpkin cinnamon), which was considered a cold (warm) smell, and the gelpack was cold (warm), it was evaluated more positively (quick in treating pain; effective in treating pain; how well it cools (warms) the hand). These findings contribute theoretically not only to the research within consumer behavior, but to general physiology and psychology literatures.

\section{General discussion}

The major objective of this paper was to explore the interactive nature of sensory and aesthetic experience within the realm of smell and touch. However, we also wanted to highlight the important conceptual notion of multisensory semantic congruence when studying sensory or aesthetic experiences.
Our research yields significant findings of the impact of smell on touch. Our two studies suggest that consumers' haptic perceptions are impacted by the presence of product-infused scents, particularly when these scents are semantically congruent with haptic perceptions. In study 1 , we show that the presence of a congruent scent leads to more positive haptic perceptions regarding the texture of paper. Thus, study 1 used the concept of gender congruence. In study 2, we replicate the findings from study 1 in showing that multisensory semantic congruence between smell and touch can lead to heightened product evaluations when the product is evaluated on effectiveness through temperature sensation, a different aspect of touch. Here, congruence of smell and touch is on the temperature dimension of touch. In sum, the findings across the two studies contribute to literature within consumer behavior and psychology on touch, smell, multisensory interactions, as well as the construct of multisensory semantic congruence.

Our findings provide ample opportunity for future research. As multiple sensory inputs ultimately combine to form our evaluations (Thesen, Vibel, Calvert, \& Österbauer, 2004), a more complete understanding of how each sense interacts with the others will do much to explicate resulting consumer behavior. For instance, as vision plays a dominant role in many perceptual experience (Hoegg \& Alba, 2007), what are the implications for diverting focus from vision to the other senses? Given the nuances entailed in how humans combine verbal and visual information (Bagozzi, 2008; Childers \& Jiang, 2008; Wyer, Hung \& Jiang, 2008), what are the issues to consider in interpreting information for additional senses? A better comprehension of when certain senses are more heavily utilized than others will help us understand the nature of multisensory interactions.

Additionally, both our studies find smell-touch effects to be unidirectional in nature. ANOVAs done on smell perception (pleasantness and likeability scale) in both studies showed no significant effects for haptic feel (rough/smooth in study 1, and hot/cold in study 2). This suggests a possible order effect of sensory focus or attention, as participants first smelled the object, and then evaluated the haptic dimensions. Thus, the unidirectional results we obtain may be due to which sense is first attended to. Further exploration of this concept would serve to better explicate the effects of multisensory interactions. Are there specific sensory experiences that dominate regardless of where they are placed in sequence? How does one ensure that the multisensory experience truly becomes a blend of each individual experience, rather than a chain of effects? Many questions remain unanswered in the arena of multisensory interactions and order of sensory integration.

A large amount of literature both within psychology and marketing has explored the consequences of congruence. However, more research should move beyond matches in valence or arousal to studying the congruence of semantic associations. In particular, future research should explore instances where multiple sensory modalities are matched on their semantic associations. This exploration would entail a more comprehensive assessment of what senses can carry such associations. The notion of sensory congruence has myriad 
implications for understanding consumer behavior and psychology in general.

Our results have several managerial implications. We provide evidence that when products are evaluated on a haptic dimension, scent can have a significant impact. Further, the semantic match or fit of the sensory components of a product do have evaluative consequences. The choice for selecting an accompanying scent, therefore, should extend beyond valence to include specific semantic associations of the sensory properties.

As product quality continues to increase, consumers will focus on less functional and more aesthetic dimensions of products when making purchases (Bloch et al., 2003). Our research suggests that the exploration of aesthetics should extend far beyond the scope of visual aesthetics (Hagtvedt \& Patrick, 2008; Raghubir \& Greenleaf, 2006). Multisensory aesthetics provides an exciting and underexplored domain in which to gain such an understanding.

\section{Acknowledgments}

This research was supported by grants from the University of Michigan. The authors would like to thank Joann Peck for her many suggestions, and Elizabeth Elder for her help in stimuli creation.

\section{References}

Bagozzi, R. (2008). "Some insights on visual and verbal processing strategies", Research dialogue. Journal of Consumer Psychology, 18, 258-263.

Berlyne, D. (Ed.). (1974). Studies in the new experimental aesthetics. New York: John Wiley.

Bloch, P. H., Brunel, F. F, \& Arnold, T. J. (2003). Individual differences in the centrality of visual product aesthetics: Concept and measurement. Journal of Consumer Research, 29(4), 551-565.

Bone, P. F., \& Ellen, P. S. (1999). Scents in the marketplace: Explaining a fraction of olfaction. Journal of Retailing, 75(2), 243-262.

Bosmans, A. (2006). Scents and sensibility: When do (in)congruent ambient scents influence product evaluations? Journal of Marketing, 70(3), 32-43.

Childers, T., \& Jiang, Y. (2008). "Neurobiological perspectives on the nature of visual and verbal processes", Research dialogue. Journal of Consumer Psychology, 18, 264-269.

Elder, R. S., \& Krishna, A. (2010). The effects of advertising copy on sensory thoughts and perceived taste. Journal of Consumer Research, 36(5), 748-756.

Fiske, S. T. (1982). Schema-triggered affect: Applications to social perception. In M. S. Clark, \& S. Fiske (Eds.), Affect and cognition: The17th Annual Carnegie Symposium on Cognition (pp. 55-78). Hillsdale, NJ: Lawrence Eribaum Associates.

Gottfried, J. A., \& Dolan, R. J. (2003). The nose smells what the eye sees: Crossmodal visual facilitation of human olfactory perception. Neuron, 39 (2), 375-386.

Grohmann, B., Spangenberg, E. R., \& Sprott, D. E. (2007). The influence of tactile input on the evaluation of retail product offerings. Journal of Retailing, 83(2), 237.

Hagtvedt, H., \& Patrick, V. M. (2008). Art infusion: The influence of visual art on the perception and evaluation of consumer products. Journal of Marketing Research (JMR), 45(3), 379-389.

Herz, R. S. (2004). A naturalistic analysis of autobiographical memories triggered by olfactory visual and auditory stimuli. Chemical Senses, 29(3), 217-224.

Hoegg, J., \& Alba, J. W. (2007, Marchh). Taste perception: More than meets the tongue. Journal of Consumer Research, 33, 490-498.

Holland, R. W., Hendriks, M., \& Aarts, H. (2005). Smells like clean spirit. Psychological Science, 16(9), 689.
Hornik, J. (1992). Tactile stimulation and consumer response. Journal of Consumer Research, 19(3), 449-458.

Klatzky, R. L., Lederman, S., \& Matula, D. E. (1987). Imagined haptic exploration in judgments of object properties. Journal of Experimental Psychology. Learning, Memory, and Cognition, 17(2), 314-322.

Krishna, A., Lwin, M. O., \& Morrin, M. (2010). Product scent and memory. Journal of Consumer Research, 37(1), 57-67.

Krishna, A., \& Morrin, M. (2008). Does touch affect taste? The perceptual transfer of product container haptic cues. Journal of Consumer Research, 34 (6), 807-818.

Laird, D. A. (1932, Junee). How the consumer estimates quality by subconscious sensory impressions: With special reference to the role of smell. The Journal of Applied Psychology, 16, 241-246.

Laurienti, P. J., Burdette, J. H., Wallace, M. T., Yen, Y. -F., Field, A. S., \& Stein, B. E. (2002). Activity in visual and auditory cortex can be modulated by influences from multiple senses. Journal of Cognitive Neuroscience, 14 , 420-429.

Lwin, M., Morrin, M., \& Krishna, A. (2010). Exploring the superadditive effects of scent and pictures on verbal recall: An extension of dual coding theory. Journal of Consumer Psychology, 20(3), 317-326.

Mandler, G. (1982). The structure of value: Accounting for taste. In M. S. Clark, \& S. T. Fiske (Eds.), Affect and cognition: The 17th Annual Symposium (pp. 3-36). Hillsdale NJ: Erlbaum.

Mattila, A. S., \& Wirtz, J. (2001). Congruency of scent and music as driver of instore evaluations and behavior. Journal of Retailing, 77(2), 273-289.

McCabe, D. B., \& Nowlis, S. M. (2003). The effect of examining actual products or product descriptions on consumer preference. Journal of Consumer Psychology, 13(4), 431-439.

Meyers-Levy, J., \& Tybout, A. M. (1989). Schema congruity as a basis for product evaluation. The Journal of Consumer Research, 16(1), 39-54.

Meyers-Levy, J., \& Zhu, R. (2010). Gender differences in the meanings consumers infer from music and other aesthetic stimuli. Journal of Consumer Psychology, 20(4), 495-507.

Mitchell, D. J., Kahn, B. E., \& Knasko, S. C. (1995, September). There's something in the air: Effects of congruent or incongruent ambient odor on consumer decision making. Journal of Consumer Research, 22, 229-238.

Morrin, M., Lwin M. \& Krishna, A. (2010), Retroactive interference from scent cues and the effect on product recall, working paper

Morrin, M., \& Ratneshwar, S. (2003, February). Does it make sense to use scents to enhance brand memory? Journal of Marketing Research, 40, 10-25.

Peck, J., \& Childers, T. L. (2003, December). Individual differences in haptic information processing: The "need for touch" scale,". Journal of Consumer Research, 30, 430-442.

Peck, J., \& Childers, T. L. (2008). If it tastes, smells, sounds, and feels like a duck, then it must be a....: Effects of sensory factors on consumer behaviors. In C. P. Haugtvedt, P. M. Herr, \& F. R. Kardes (Eds.), Handbook of consumer psychology (pp. 193-219). New York: Psychology Press.

Peck, J., \& Shu, S. B. (2009). The effect of mere touch on perceived ownership Journal of Consumer Research:, 36(3), 434-447.

Peck, J., \& Wiggins, J. (2006). It just feels good: Customers' affective response to touch and its influence on persuasion. Journal of Marketing, 70(4), 56-69.

Peracchio, L. A., \& Tybout, A. M. (1996). The moderating role of prior knowledge in schema-based product evaluation. Journal of Consumer Research, 23, 177.

Raghubir, P., \& Greenleaf, E. A. (2006). Ratios in proportion: What should the shape of the package be? Journal of Marketing, 70(2), 95-107.

Reimann, M., Zaichkowsky, J., Neuhaus, C., \& Weber, B. (2010). Aesthetic package design: A behavioral, neural, and psychological investigation. Journal of Consumer Psychology, 20(4), 431-441.

Rozin, P. (1999). Preadaptation and the puzzles and properties of pleasure. In D. Kahneman, E. Diener, \& N. Schwarz (Eds.), Well-being: The foundations of hedonic psychology (pp. 109-133). New York: Russell Sage Foundation.

Rozin, P., \& Hormes, J. M. (2009). Psychology and sensory marketing, with a focus on food. In A. Krishna (Ed.), Sensory marketing: Research on the sensuality of products (pp. 303-321). : Routledge Academic. 
Russell, C. A. (2002). Investigating the effectiveness of product placements in television shows: the role of modality and plot connection congruence on brand memory and attitude. Journal of Consumer Research, 29(3), 306-318.

Secundo, L., \& Sobel, N. (2006). The influence of smelling coffee on olfactory habituation.Neuroscience.. Berkeley, CA: University of California, Berkeley http://www.senseofsmell.org/achems_06.php.

Spangenberg, E. R., Grohmann, B., \& Sprott, D. E. (2005). It's beginning to smell (and sound) a lot like Christmas: The interactive effects of ambient scent and music in a retail setting. Journal of Business Research, 58(11), 1583-1589.

Spangenberg, E. R., Sprott, D. E., Grohmann, B., \& Tracey, D. L. (2006) Gender-congruent ambient scent influences on approach and avoidance behaviors in a retail store. Journal of Business Research, 59, 1281-1287.

Stevenson, R. J., \& Boakes, R. A. (2003). A mnemonic theory of odor perception. Psychological Review, 110(2), 340-364.
Thesen, T., Vibel, J. F., Calvert, G. A., \& Österbauer, R. A. (2004). Neuroimaging of multisensory processing in vision, audition, touch, and olfaction. Cognitive Process, 5, 84-93.

Williams, L. E., \& Bargh, J. A. S. (2008, Octoberr). Experiencing physical warmth promotes interpersonal warmth. Science, 24, 606-607.

Wyer, R. S., Hung, I. W., \& Jiang, Y. (2008). Visual and verbal processing strategies in comprehension and judgment". Journal of Consumer Psychology, $18,244-257$.

Yalch, R. F., \& Spangenberg, E. R. (2000). The effects of music in a retail setting on real and perceived shopping times. Journal of Business Research, 49(2), 139-147.

Yang, X., Zhang, J., \& Peracchio, L. A. (2010). Understanding the impact of self-concept on the stylistic properties of images. Journal of Consumer Psychology, 20(4), 508-520.

Yorkston, E., \& Menon, G. (2004). A sound idea: Phonetic effects of brand names on consumer judgments. Journal of Consumer Research, 31(1), 43-51. 